\title{
Glucosamine and chondroitin use in canines for osteoarthritis: A review
}

\author{
Angel Bhathal ${ }^{1}$, Meredith Spryszak ${ }^{2}$, Christopher Louizos² and Grace Frankel ${ }^{2, *}$ \\ ${ }^{1}$ Faculty of Pharmacy and Pharmaceutical Sciences, University of Alberta, Edmonton, Alberta T6G 2H7, Canada \\ ${ }^{2}$ College of Pharmacy, Faculty of Health Sciences, University of Manitoba, Winnipeg, Manitoba R3E 0T5, Canada
}

\begin{abstract}
Osteoarthritis is a slowly progressive and debilitating disease that affects canines of all breeds. Pain and decreased mobility resulting from osteoarthritis often have a negative impact on the affected canine's quality of life, level of comfort, daily functioning, activity, behaviour, and client-pet companionship. Despite limited and conflicting evidence, the natural products glucosamine hydrochloride $(\mathrm{HCl})$ and chondroitin sulfate are commonly recommended by veterinarians for treating osteoarthritis in dogs. There is a paucity of well-designed clinical veterinary studies investigating the true treatment effect of glucosamine and chondroitin. The purposes of this review article are to provide a brief background on glucosamine and chondroitin use in canine osteoarthritis and to critically review the available literature on the role of these products for improving clinical outcomes. Based on critical review, recommendations for practice are suggested and a future study design is proposed.

Keywords: Canine, Chondroitin, Glucosamine, Osteoarthritis, Veterinary.
\end{abstract}

\section{Introduction}

Osteoarthritis is a slowly progressive, degenerative, and debilitating disease affecting $20 \%$ of the canine population over the age of one (Johnston, 1997; Johnson et al., 2001; Roush et al., 2002; Aragon et al., 2007). Large-breed dogs may develop more severe clinical signs and initial symptoms of osteoarthritis; however, dogs of all sizes and breeds are affected by the disease as they age (Rychel, 2010).

The etiology of osteoarthritis' pathology may include defective articular cartilage structure, inadequate cartilage biosynthesis, joint trauma, instability, and inflammatory mechanisms. The disease presents with symptoms such as pain, stiffness, lameness, and disability (D'Altilio et al., 2007).

Pain and decreased mobility resulting from osteoarthritis often have a negative impact on the affected canine's quality of life, level of comfort, daily functioning (i.e. standing, walking), exercise tolerance, activity (i.e. playing, climbing stairs), behaviour, urinary and fecal habits, and client-pet companionship. Owners of severely affected dogs may decide to euthanize their pet (Rychel, 2010; Epstein et al., 2015). Once a canine develops osteoarthritis, exploring treatment options becomes essential for minimizing the negative consequences of the disease. Nonpharmaceutical treatment options may include surgery, weight loss, exercise modification, and physical therapy (Beale, 2004).

Non-steroidal anti-inflammatory drugs (NSAIDs) are the current gold-standard pharmaceutical therapy for dogs with osteoarthritis; however, NSAIDs may cause gastrointestinal ulceration as an adverse effect and are contraindicated in the presence of renal insufficiency or dehydration. Other pharmaceutical options include diacerhein, corticosteroids, and hyaluronic acid (Henrotin et al., 2005). Select nutraceuticals such as glucosamine, chondroitin, pentosane polysulphate, avocado/soybean unsaponifiables, green-lipped mussel, and milk protein have also been used (Henrotin et al., 2005).

Glucosamine hydrochloride $(\mathrm{HCl})$ and chondroitin sulfate (CS) are commonly recommended natural health products for treating osteoarthritis in dogs (Rychel, 2010). Glucosamine regulates the synthesis of collagen in cartilage and may provide mild antiinflammatory effects while chondroitin sulfate inhibits destructive enzymes in joint fluid and cartilage. The two nutraceuticals also contribute to the synthesis of glycoaminoglycans and proteoglycans, which are building blocks for the formation of cartilage (Beale, 2004).

In humans, glucosamine is available in several dosage forms; glucosamine hydrochloride $(\mathrm{HCl})$, glucosamine sulfate (stabilized with different salts, usually potassium chloride) and crystalline glucosamine sulfate. $\mathrm{N}$-acetyl glucosamine is another available salt form, but it appears to have no clinical activity as compared to the other salt forms (Beale, 2004).

In terms of efficacy, crystalline glucosamine sulfate has shown the greatest efficacy for osteoarthritis of the knee which is likely due to an improved oral bioavailability $(25 \%-44 \%)$ as compared to other glucosamine salts ( Setnikar and Rovati, 2001; Persiani 
et al., 2005; Altman, 2009). Crystalline glucosamine sulfate is a pharmaceutical-grade prescription product in Europe (but not in the United States or Canada) that consists of glucosamine, sulfate, sodium and chloride ions in a specific stoichiometric ratio (Altman, 2009). The other glucosamine salt forms ( $\mathrm{HCl}$, sulfate salts) have demonstrated variable efficacy in humans ( Sawitzke et al., 2010; Rovati et al., 2012). This is primarily due to inconsistency in glucosamine content amongst nutraceutical products and poor oral bioavailability, especially in combination with other nutraceutical additives (Altman, 2009; Sawitzke et al., 2010; Wandel et al., 2010).

Similar to human products, there are various manufactured glucosamine and chondroitin products marketed for canines that differ in terms of strength, formulation, and additional active ingredients. Table 1 provides reference to various examples of glucosamine and chondroitin products marketed for canines. It should be noted that the majority of veterinary supplements contain glucosamine $\mathrm{HCl}$, which is already known to have poorer bioavailability and poor clinical effect in humans.

There are several hypothesized reasons for this salt choice in veterinary products. First, the hydrochloride salt from a chemical perspective provides a greater amount of glucosamine per gram than does the sulfate salt despite the fact previous studies report overall lower oral bioavailability (Beale, 2004). The sulfate salt is often stabilized with sodium chloride $(\mathrm{NaCl})$ or potassium chloride $(\mathrm{KCl})$, which may be undesirable in aging canines with potential co-morbid medical conditions such as heart failure, hypertension or renal decline. Although this is a theoretical concern, human clinical trials have not demonstrated increases in blood pressure with $\mathrm{NaCl}$ content of crystallized glucosamine sulfate (Herrero-Beaumont et al., 2007; Rovati et al., 2012).

Last, the hydrochloride salt is much cheaper to produce; keeping in mind that crystalline glucosamine sulfate is manufactured as pharmaceutical-grade with strict quality control standards (Altman, 2009).

There is currently a lack of evidence to confirm a specific therapeutic dose of glucosamine in canines, yet, an adjunctive chondroitin dose of $15-30 \mathrm{mg} / \mathrm{kg}$ has been suggested (Plumb, 2015). Few in vitro studies have provided bioavailability and pharmacokinetic data differentiating the most optimally absorbed glucosamine formulation in canines.

In horses, crystalline glucosamine sulfate achieves higher concentrations than glucosamine $\mathrm{HCl}$ (Meulyzer et al., 2008). One study in dogs demonstrated oral bioavailability of $12 \%$ and $5 \%$ for glucosamine hydrochloride and chondroitin sulfate respectively. (Adebowale et al., 2002).
Table 1. Examples of Nutraceutical Products Marketed for Canines with Osteoarthritis (Henrotin et al., 2005) and their Various Ingredients.

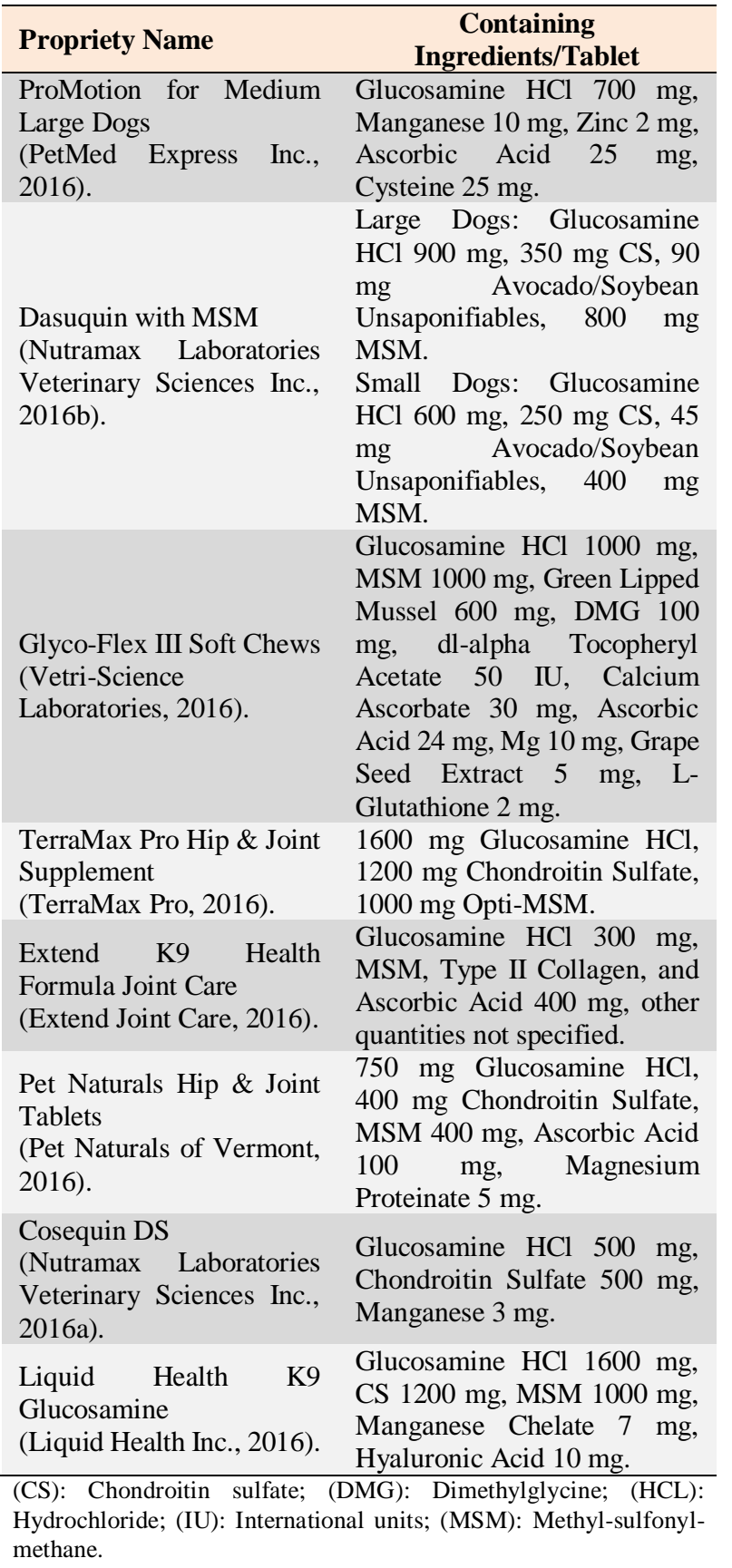

Some studies have indicated that when administered to dogs as a combination, glucosamine and chondroitin are absorbed in as little as two hours (Beale, 2004). One commentary notes that glucosamine $\mathrm{HCl}$ and chondroitin sulfate require 10 to 20 times the quantity used in in vitro studies to reach a plasma concentration that will result in biological activity (Comblain et al., 2016). 
It has been suggested that 2-6 weeks of treatment with glucosamine and chondroitin may be necessary for any therapeutic effect to become apparent (Plumb, 2015), but there is a lack of clinical evidence to support this statement. Potential adverse effects include hypersensitivity and minor gastrointestinal effects such as flatulence and stool softening (Plumb, 2015).

Veterinarians commonly recommend glucosamine and chondroitin for treating osteoarthritis in canines despite the lack of compelling scientific evidence demonstrating clinical benefit.

Clinical trials to date have used different products, salt forms, doses, and dosing regimens such that comparing the results to draw meaningful conclusions about therapeutic efficacy is difficult (Addleman, 2010). In addition, pharmacists are often approached by pet owners with questions about the use of over-thecounter natural products in pets due to the availability of these products in pharmacies.

Unfortunately, the lack of high-quality research on natural product use in pets makes it difficult to offer informed recommendations to pet owners with regard to glucosamine and chondroitin.

The purpose of this review is to critically appraise the available literature on the role of glucosamine and chondroitin in improving clinical outcomes in canines with osteoarthritis. We will propose evidence-based recommendations for practice and provide suggestions regarding the design of future clinical studies.

\section{Evidence summary}

Clinical trial: Glucosamine and chondroitin versus NSAID or placebo

Moreau et al. (2003) conducted a prospective, randomized, double-blinded study including 71 clientowned $\operatorname{dogs}>12$ months old and $>20 \mathrm{~kg}$ with ownerreported lameness and radiographic signs of osteoarthritis.

The trial consisted of four arms in which the subjects received either: 1) glucosamine $\mathrm{HCl}$, chondroitin sulfate, and magnesium ascorbate (GSCM), 2) carprofen, 3) meloxicam, or 4) placebo. For complete dosing and titration schedules, please see Table 2.

Primary outcomes included treatment efficacy, tolerability and ease of administration. Efficacy was measured objectively through ground reaction force (GRF) values and subjectively through owner and orthopaedic surgeon assessments at 0,30 and 60 days of treatment. Blood and faecal analyses were conducted on the same schedule to determine treatment safety. The placebo and GCSM arms did not experience statistically significant improvements in any of the outcome measures by trial end.

In contrast, both NSAID arms experienced significant improvements in GRF values and orthopaedic surgeon assessment scores; however, only the meloxicam arm experienced a significant improvement according to owner assessment.

The Moreau et al. (2003) trial had several strengths. The study was double-blinded, prospective and subjects were randomized to treatment groups. Additionally, the authors claimed that mean age, weight, affected limb GRF values, radiographic scores, and subjective scores of the dogs in the four study arms were all similar at baseline, although data to support this claim was not provided. Weaknesses of the trial included that glucosamine and chondroitin doses are much lower in comparison to other clinical trials and the treatment regimens differed between study arms.

The meloxicam arm received a loading dose, the GCSM dose was decreased over the course of the trial, and the placebo arm was discontinued after 30 days while all other interventions continued for 60 days. While the GCSM arm did not experience any significant outcome improvements by trial end, it is possible that the intervention was ineffective due to the absence of a GCSM loading dose, the use of subtherapeutic GCSM doses throughout the trial, and/or an insufficient trial length. The fact that the improvement in GRF values experienced by the carprofen arm was not accompanied by an improvement in subjective owner assessment scores questions the clinical significance of GRF values. Eight of the 71 subjects $(11.3 \%)$ were lost to follow-up and the authors did not disclose which study arms were affected by dropout.

Mean assessment scores with confidence intervals for GRF, orthopaedic surgeon assessment and owner assessment were not provided. The primary outcome stated by investigators was to identify the "best" treatment for dogs with osteoarthritis which requires appropriately designed statistical methods to compare treatment arms. However, statistical comparisons and treatment rankings were not provided and the magnitudes of the treatment effects were not reported.

Clinical trial: glucosamine and chondroitin versus placebo or NSAID

Investigators in the McCarthy et al. (2007) group conducted a prospective, randomized, double-blinded study that included 42 client-owned dogs, with 35 completing the trial. The dogs could be of any breed or sex, presenting with clinical signs of chronic lameness, stiffness, joint pain, and radiological evidence of osteoarthritis of the hips and/or elbows. The trial consisted of two arms in which the subjects received either: 1) glucosamine $\mathrm{HCl}$, chondroitin sulfate, $\mathrm{N}$ acetyl-D-glucosamine, ascorbic acid, and zinc sulfate or 2) carprofen. For complete dosing and titration schedules, please see Table 2 . The primary outcome of efficacy in the treatment of osteoarthritis was determined through subjective veterinarian assessment at $0,14,42,70$ and 98 days of treatment. 
Table 2. Literature Overview on Glucosamine and Chondroitin Use in Canines for Osteoarthritis.

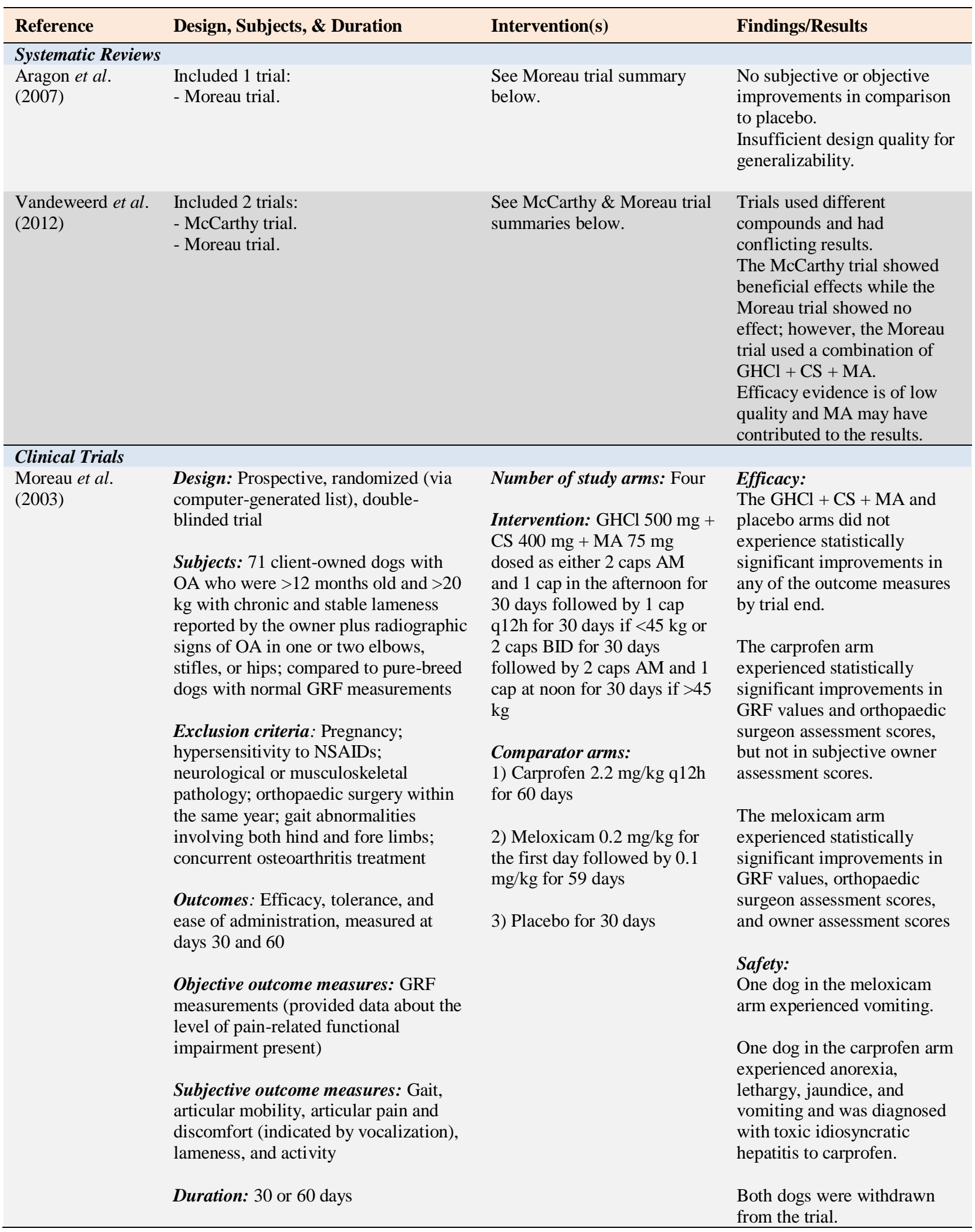


Table 2: Literature Overview on Glucosamine and Chondroitin Use in Canines for Osteoarthritis (Cont.).

\begin{tabular}{|c|c|c|c|}
\hline $\begin{array}{l}\text { McCarthy et al. } \\
\text { (2007) }\end{array}$ & $\begin{array}{l}\text { Design: Multi-centered, prospective, } \\
\text { randomized (alternating order of } \\
\text { enrollment), double-blinded trial. } \\
\text { Subjects: } 42 \text { client-owned dogs of any } \\
\text { breed or sex presenting with clinical signs } \\
\text { of chronic lameness (present for at least } 1 \\
\text { month), stiffness, joint pain, and } \\
\text { radiological evidence of OA of the hips } \\
\text { and/or elbows; } 35 \text { completed the trial. } \\
\text { Exclusion criteria: Pregnancy; current } \\
\text { use of other medications; hepatic, renal, } \\
\text { and/or CV disease; gastrointestinal } \\
\text { ulceration; bleeding disorder; lameness } \\
\text { due to infectious, immune-mediated, } \\
\text { neurological, or neoplastic disease; } \\
\text { previous use of drugs and/or dietary } \\
\text { supplements for the treatment of OA. } \\
\text { Outcomes: Efficacy in the treatment of } \\
\text { confirmed OA, measured at days } 14,42 \text {, } \\
\text { and } 70 ; \text { additionally, compliance was } \\
\text { assessed by counting the number of } \\
\text { capsules remaining at each visit. } \\
\text { Subjective outcome measures: Scores for } \\
\text { lameness, joint mobility, pain on } \\
\text { palpation, weight-bearing, and an overall } \\
\text { score for clinical condition; severity of } \\
\text { condition, subjective veterinarian } \\
\text { evaluation, and withdrawal symptoms } \\
\text { were also measured. } \\
\text { Duration: } 70 \text { days. }\end{array}$ & $\begin{array}{l}\text { Number of study arms: Two } \\
\text { Intervention: GHCl } 475 \\
\mathrm{mg} / \mathrm{g}, \mathrm{CS} 350 \mathrm{mg} / \mathrm{g}, \mathrm{NADG} \\
50 \mathrm{mg} / \mathrm{g}, \mathrm{AA} 50 \mathrm{mg} / \mathrm{g} \text {, and } \mathrm{ZS} \\
30 \mathrm{mg} / \mathrm{g} \text { with total doses of } 1 \\
\mathrm{~g}, 1.5 \mathrm{~g} \text {, or } 2 \mathrm{~g} \text { of active } \\
\text { ingredient BID for } 42 \text { days } \\
\text { for dogs weighing } 5-19.9 \mathrm{~kg} \text {, } \\
20-40 \mathrm{~kg} \text {, or }>40 \mathrm{~kg} \\
\text { respectively, followed by a } \\
\text { dose decrease by one-third of } \\
\text { the original dose for the } \\
\text { subsequent } 28 \mathrm{days} \text {; } \\
\text { administered with food. } \\
\text { Comparator arm: Carprofen } \\
2 \mathrm{mg} / \mathrm{kg} \text { BID for } 7 \text { days } \\
\text { followed by } 2 \text { mg/kg SID for } \\
\text { the subsequent } 63 \text { days; } \\
\text { administered with food. }\end{array}$ & $\begin{array}{l}\text { Efficacy: } \\
\text { The GHCl + CS + NADG + } \\
\text { AA + ZS arm showed } \\
\text { statistically significant } \\
\text { improvements from baseline } \\
\text { with regard to pain, weight- } \\
\text { bearing, and overall condition } \\
\text { scores at } 70 \text { days. Lameness } \\
\text { and joint mobility scores did } \\
\text { not improve significantly by } \\
\text { trial end. } \\
\text { The carprofen arm showed } \\
\text { significant improvements } \\
\text { from baseline with regard to } \\
\text { all five parameters at or } \\
\text { before } 70 \text { days. } \\
\text { Safety: } \\
\text { Two dogs in the GHCl + CS } \\
+ \text { NADG + AA + ZS arm } \\
\text { experienced unspecified } \\
\text { adverse drug reactions and } \\
\text { were withdrawn from the } \\
\text { trial. }\end{array}$ \\
\hline $\begin{array}{l}\text { Gupta et al. } \\
\text { (2012) }\end{array}$ & $\begin{array}{l}\text { Design: Prospective, randomized, } \\
\text { controlled, double-blinded trial. } \\
\text { Subjects: } 31-37 \text { client-owned dogs (each } \\
\text { of the four trial arms consisted of } 7-10 \\
\text { dogs) weighing > } 40 \text { lbs with moderate } \\
\text { OA. } \\
\text { Exclusion criteria: Serious concomitant } \\
\text { diseases or complications. } \\
\text { Outcomes: Therapeutic efficacy, } \\
\text { tolerability, and safety, measured on a } \\
\text { monthly basis. } \\
\text { Objective outcome measures: Peak } \\
\text { vertical force and impulse area } \\
\text { measurements obtained with a } \\
\text { piezoelectric sensor-based ground force } \\
\text { plate (indicators of lameness due to pain); } \\
\text { physical, hepatic, and renal functions } \\
\text { were monitored via body weight, } \\
\text { temperature, pulse, ALP, ALT, bilirubin, } \\
\text { BUN, and Cr measurements. } \\
\text { Subjective outcome measures: Overall } \\
\text { pain, pain upon limb manipulation } \\
\text { (vocalization), pain after physical } \\
\text { exertion (limping and limb rigidity), signs } \\
\text { of pain, signs of lameness, severity of } \\
\text { pain during various activities (i.e. } \\
\text { playing), and overall performance } \\
\text { assessments (running, participation in } \\
\text { activities, movement, change between } \\
\text { sitting and standing). } \\
\text { Duration: } 150 \text { days. }\end{array}$ & $\begin{array}{l}\text { Number of study arms: Four } \\
\text { Interventions: } \\
\text { 1) GHCl } 2000 \mathrm{mg}+\mathrm{CS} 1600 \\
\mathrm{mg}+\mathrm{UCII} 10 \mathrm{mg} \text { given daily } \\
\text { 2) GHCl } 2000 \mathrm{mg}+\mathrm{CS} 1600 \\
\text { mg given daily } \\
\text { 3) UCII } 10 \mathrm{mg} \text { given daily } \\
\text { Comparison arm: Placebo } \\
\text { given daily. }\end{array}$ & $\begin{array}{l}\text { Efficacy: } \\
\text { The placebo arm did not } \\
\text { experience statistically } \\
\text { significant changes in any of } \\
\text { the outcome measures by trial } \\
\text { end. } \\
\text { The GHCl + CS arm } \\
\text { exhibited a significant } \\
\text { reduction in pain by day } 90 \\
\text { with maximal effects } \\
\text { observed on day } 150 \text {. } \\
\text { Specifically, overall pain had } \\
\text { decreased by } 51 \% \text {, pain after } \\
\text { limb manipulation had } \\
\text { decreased by } 48 \% \text {, and pain } \\
\text { after physical exertion had } \\
\text { decreased by } 43 \% \text { from } \\
\text { baseline at } 150 \text { days. Ground } \\
\text { force plate-based parameters } \\
\text { remained significantly } \\
\text { unchanged by trial end. } \\
\text { Supplementing GHCl + CS } \\
\text { with UCII did not provide any } \\
\text { additional benefit. } \\
\text { Safety: } \\
\text { None of the dogs receiving } \\
\text { dietary supplements showed } \\
\text { any signs of adverse effects. }\end{array}$ \\
\hline
\end{tabular}


Table 2. Literature Overview on Glucosamine and Chondroitin Use in Canines for Osteoarthritis (Cont.).

$\begin{array}{ll}\text { D'Altilio et al. } & \text { Design: Prospective, randomized, } \\ \text { (2007) } & \text { controlled, double-blinded trial. }\end{array}$

Subjects: 20 client-owned dogs presenting with joint stiffness, lameness, moderate pain, swollen joints, difficulty getting up/down, and difficulty walking in horizontal areas or stairs due to OA.

Outcomes: Therapeutic efficacy and safety, measured on a monthly basis.

Objective outcome measures: Body weight, hepatic function (ALT, bilirubin), and renal function (BUN, $\mathrm{Cr}$ ) were measured to monitor for adverse effects.

Subjective outcome measures: Overall pain (trouble changing between sitting and standing, vocalization, crying), pain upon limb manipulation (vocalization), and exercise-associated lameness (limping, holding limb up, limb rigidity).

Duration: 120 days of intervention exposure followed by a 30-day withdrawal period.
Number of study arms: Four

\section{Interventions:}

1) $\mathrm{GHCl} 2000 \mathrm{mg}+\mathrm{CS} 1600$ mg + UCII 10 mg given daily

2) $\mathrm{GHCl} 2000 \mathrm{mg}+\mathrm{CS} 1600$ mg given daily

3) UCII $10 \mathrm{mg}$ given daily

Comparison arm: Placebo given daily
Efficacy:

The placebo arm did not experience statistically significant changes in any of the outcome measures by trial end.

The $\mathrm{GHCl}+\mathrm{CS}$ arm experienced a reduction in pain that was not significant and showed relapse following the 30-day treatment withdrawal period.

Supplementing $\mathrm{GHCl}+\mathrm{CS}$ with UCII did reduce overall pain, pain upon limb manipulation, and exercise induced lameness to a significant extent, although this benefit was also lost following the 30-day treatment withdrawal period.

Safety:

None of the dogs receiving dietary supplements showed any signs of adverse effects.

In Vitro Studies Anderson et al. (1999)

$\mathrm{N}=2$ adult female dogs recently euthanized for reasons unrelated to orthopedic abnormalities.

Number of study arms: Three

\section{Interventions:}

1) Chondrocytes cultured in Measured chondrocytes for viable cells, PGE2 and GAG concentrations at days 3, 6 , and 12 .

glucosamine $100 \mathrm{mcg} / \mathrm{mL}$.

2) Chondrocytes cultured in acetylsalicylate $18 \mathrm{mcg} / \mathrm{mL}$.

3) Chondrocytes cultured in a control medium.

Adebowale et Randomized three-way single dose crossal. (2002)

\section{Number of study arms: Four}

\section{Interventions:}

$\mathrm{N}=8$ male beagle dogs of age $>6$ months weighing approximately $9 \mathrm{~kg}$.

Bioavailability and pharmacokinetics of single and multiple doses were measured through blood and plasma samples.

A typical blood sampling scheme was measured pre-dose and at $0.5,1,2,4,6$, $8,10,12,14$, and 24 hours following drug administration.
1) IV GHCl $500 \mathrm{mg}+$ LMWCS $400 \mathrm{mg}$ for 14 days.

2) $\mathrm{PO} \mathrm{GHCl} 1500 \mathrm{mg}+$ LMWCS $1200 \mathrm{mg}$ for 14 days.

3) PO GHCl $2000 \mathrm{mg}+$ LMWCS $1600 \mathrm{mg}$ for 14 days.

4) $\mathrm{PO} \mathrm{GHCl} 1500 \mathrm{mg}+$ LMWCS $1200 \mathrm{mg}$ on days 17 followed by $\mathrm{PO} \mathrm{GHCl} 3000$ $\mathrm{mg}+$ LMWCS $2400 \mathrm{mg}$ on days 8-14.
Chondrocytes in all three mediums had characteristics indicative of viability and differentiation.

\section{GHCl and LMWCS are} bioavailable after oral dosing.

LMWCS results in significant accumulation upon multiple dosing.

$\mathrm{GHCl}$ and LMWCS BA were $12 \%$ and $5 \%$, respectively.

$\mathrm{Cmax}=8.95 \mathrm{mcg} / \mathrm{mL}$ and Tmax $=1.5$ hours following $1500 \mathrm{mg}$ dose of $\mathrm{GHCl}$.

$\mathrm{Cmax}=21.5 \mathrm{mcg} / \mathrm{mL}$ following $1600 \mathrm{mg}$ dose of CS. 
Table 2. Literature Overview on Glucosamine and Chondroitin Use in Canines for Osteoarthritis (Cont.).

\begin{tabular}{|c|c|c|c|}
\hline \multicolumn{4}{|c|}{ Surrogate Outcome Trials } \\
\hline $\begin{array}{l}\text { Johnson et al. } \\
\text { (2001) }\end{array}$ & $\begin{array}{l}\mathrm{N}=16 \text { pure-bred dogs weighing } 23-32 \\
\mathrm{~kg} \text { with surgically-induced } \mathrm{OA} \text {; not } \\
\text { client-owned. } \\
\text { Measured concentrations of synovial } \\
\text { fluid markers at } 0,1,3, \& 5 \text { months. }\end{array}$ & $\begin{array}{l}\text { Number of study arms: Four } \\
\text { Interventions: } \\
\text { 1) GHCl } 250 \mathrm{mg}+\mathrm{CS} 200 \\
\text { mg + MA } 5 \mathrm{mg}+\mathrm{CCL} \\
\text { reconstruction. } \\
\text { 2) GHCl } 250 \mathrm{mg}+\mathrm{CS} 200 \\
\text { mg + MA } 5 \mathrm{mg}+\text { sham CCL } \\
\text { reconstruction. } \\
\text { 3) Sham CCL reconstruction } \\
\text { 4) CCL reconstruction. }\end{array}$ & $\begin{array}{l}\text { Heterogeneity of results from } \\
\text { synovial fluid analyses } \\
\text { reported. } \\
\mathrm{GHCl}+\mathrm{CS}+\mathrm{MA} \text { arms had } \\
\text { significantly higher levels of } \\
\text { beneficial synovial fluid } \\
\text { markers; however, } \\
\text { concentrations were not } \\
\text { localized to joints. }\end{array}$ \\
\hline $\begin{array}{l}\text { Canapp et al. } \\
\text { (1999) }\end{array}$ & $\begin{array}{l}\mathrm{N}=32 \text { skeletally mature mixed-breed } \\
\text { dogs of age } 1-5 \text { years weighing } 4.5-11 \\
\mathrm{~kg} \text { with chemically-induced synovitis. } \\
\text { Measured SA at days } 13,20,27,34,41 \text {, } \\
\text { and } 48 \text { post-SI; measured lameness at } \\
\text { days } 1-48 \text { post-SI. }\end{array}$ & $\begin{array}{l}\text { Number of study arms: Four } \\
\text { Interventions: } \\
\text { 1) GHCl } 500 \mathrm{mg}+\mathrm{CS} 400 \\
\mathrm{mg}+\text { manganese } 10 \mathrm{mg}+ \\
\text { ascorbate } 66 \mathrm{mg} \text { (GlAm-CS) } \\
\text { q } 8 \mathrm{~h} \text { for } 21 \text { days pre-SI, then } \\
\text { GlAm-CS for } 48 \text { days post- } \\
\text { SI. } \\
\text { 2) Placebo for } 21 \text { days pre-SI, } \\
\text { then GlAm-CS for } 48 \text { days } \\
\text { post-SI. } \\
\text { 3) Placebo for } 21 \text { days pre-SI, } \\
\text { then GlAm-CS + SAMe } 200 \\
\text { mg for } 48 \text { days post-SI } \\
\text { 4) Placebo for } 21 \text { days pre-SI, } \\
\text { then placebo for } 48 \text { days post- } \\
\text { SI. }\end{array}$ & $\begin{array}{l}\text { Dogs given pre-SI GlAm-CS } \\
\text { showed significantly less soft- } \\
\text { tissue SA at day } 48 \text { and } \\
\text { significantly less bone SA at } \\
\text { days } 41 \text { and } 48 \text { compared to the } \\
\text { other study arms, with less SA } \\
\text { being suggestive of a protective } \\
\text { effect against synovitis. } \\
\text { Dogs given pre-SI GlAm-CS } \\
\text { showed a significant decrease in } \\
\text { lameness on days } 12,19,23 \text {, } \\
\text { and } 24 \text { compared to the other } \\
\text { study arms. } \\
\text { Significant differences in SA } \\
\text { and lameness were not found at } \\
\text { any time among the study arms } \\
\text { that did not receive pre-SI } \\
\text { therapy. }\end{array}$ \\
\hline \multicolumn{4}{|l|}{ Review Articles } \\
\hline Pascoe (2002) & Not applicable. & Glucosamine \& chondroitin. & $\begin{array}{l}\text { Article reviews studies in } \\
\text { humans, horses, and dogs. }\end{array}$ \\
\hline $\begin{array}{l}\text { Henrotin et al. } \\
\text { (2005) }\end{array}$ & Not applicable. & Glucosamine sulfate \& CS. & $\begin{array}{l}\text { In vitro studies show increased } \\
\text { production of proteoglycans by } \\
\text { chondrocytes; however, results } \\
\text { cannot be extrapolated to } \\
\text { different preparations. No } \\
\text { scientifically conducted trials } \\
\text { demonstrate disease-modifying } \\
\text { properties. }\end{array}$ \\
\hline $\begin{array}{l}\text { Johnston et al. } \\
\text { (2008) }\end{array}$ & Not applicable. & $\mathrm{GHCl} \& \mathrm{CS}$. & $\begin{array}{l}\text { Refers to Moreau and } \\
\text { McCarthy trials. Concludes that } \\
\text { based on the quality of the } \\
\text { trials, one can be moderately } \\
\text { comfortable with the results } \\
\text { despite their lack of } \\
\text { consistency. }\end{array}$ \\
\hline $\begin{array}{l}\text { Addleman } \\
\text { (2010) }\end{array}$ & Not applicable. & Glucosamine \& chondroitin. & $\begin{array}{l}\text { Purity, quality, efficacy, dosing, } \\
\text { and absorption of glucosamine } \\
\text { and chondroitin vary and } \\
\text { evidence is limited. There is a } \\
\text { need for validated owner } \\
\text { questionnaires, long-term } \\
\text { studies with objective measures, } \\
\text { and a better understanding of } \\
\text { their mode of action. }\end{array}$ \\
\hline $\begin{array}{l}\text { McKenzie } \\
(2010)\end{array}$ & Not applicable & Glucosamine \& chondroitin & $\begin{array}{l}\text { The evidence is limited in terms } \\
\text { of quantity and quality and the } \\
\text { results are mixed. }\end{array}$ \\
\hline
\end{tabular}


Table 2. Literature Overview on Glucosamine and Chondroitin Use in Canines for Osteoarthritis (Cont.).

\begin{tabular}{|c|c|c|c|}
\hline $\begin{array}{l}\text { KuKanich } \\
(2013)\end{array}$ & Not applicable. & $\begin{array}{l}\text { Glucosamine \& chondroitin } \\
\text { dosed q } 24 \mathrm{~h} .\end{array}$ & $\begin{array}{l}\text { Current literature does not } \\
\text { support the use of glucosamine } \\
\text { and chondroitin for the control } \\
\text { of osteoarthritis pain in dogs. }\end{array}$ \\
\hline $\begin{array}{l}\text { Comblain et al. } \\
\text { (2016) }\end{array}$ & Not applicable. & Glucosamine \& chondroitin. & Studies have contrasting results. \\
\hline $\begin{array}{l}\text { Neil et al. } \\
(2005)\end{array}$ & Not applicable. & Glucosamine \& chondroitin. & $\begin{array}{l}\text { In vitro studies indicate rapid } \\
\text { absorption, a good safety } \\
\text { profile, and chondroprotective } \\
\text { effects in dogs. Minimal } \\
\text { effective concentrations of these } \\
\text { compounds and beneficial } \\
\text { effects in dogs require further } \\
\text { investigation. }\end{array}$ \\
\hline
\end{tabular}

(AA): Ascorbic acid; (ALP): Alkaline phosphatase; (ALT): Alanine transaminase; (AM): Morning, (BA): Bioavailability; (BID): Twice daily; (BUN): Blood urea nitrogen; (CCL): Cranial cruciate ligament; (Cmax): Maximum or peak serum concentration; (Cr): Creatinine; (CS): Chondroitin sulfate; (CV): Cardiovascular; (GAG): Glycosaminoglycan; (GHCl): Glucosamine hydrochloride; (GlAm-CS): Glucosamine and chondroitin sulfate; (GRF): Ground reaction force; (IV): Intravenous; (LMWCS): Low molecular weight chondroitin sulfate; (MA): Manganese ascorbate; (MSM): Methyl-sulfonyl-methane; (N): Number of study subjects; (NADG): N-acetyl-D-glucosamine; (OA): Osteoarthritis; (PGE2): Prostaglandin E2; (PO): By mouth; (q12H): Every 12 hours; (SAMe): S-adenosyl-L-methionine; (SA): Scintigraphic activity; (SI): Synovitis induction; (SID): Once daily; (Tmax): Time to reach maximum concentration; (UCII): Undenatured collagen type II; (ZS): Zinc sulfate.

The outcome measures included scores for joint mobility, lameness, pain on palpation, weight-bearing, and an overall score for clinical condition. In the carprofen arm, statistically significant improvements were found between the pre-treatment and change scores for all five efficacy parameters at or before 70 days. In contrast, the glucosamine and chondroitin arm showed statistically significant improvements in pain, weight-bearing, and overall condition for the first time at 70 days, while lameness and joint mobility did not improve to a significant extent by trial end. The authors also concluded that glucosamine and chondroitin therapy was non-inferior to carprofen therapy at day 70 in the treatment of osteoarthritis in dogs.

The McCarthy et al. (2007) trial was multi-centered, randomized, double-blinded, and prospective which is an ideal study design. However, the method of randomization was determined by order of presentation (alternating), which introduces the risk of selection bias since the ability to anticipate treatment allocation may potentially influence the order of enrollment. Baseline characteristics of the two groups of canines had some variation in terms of mean weight, age, and affected joints.

Therapeutic efficacy scores were based on subjective assessments conducted by veterinarians, which could be highly variable between clinicians. Six dogs from the glucosamine and chondroitin arm failed to complete the study, two of which were withdrawn due to experiencing unspecified adverse drug reactions. One dog from the carprofen arm failed to complete the study. With seven dropouts, the loss to follow-up was high $(16.7 \%)$. The collected data underwent a perprotocol analysis (versus intention-to-treat) therefore we cannot comment on the robustness of the results.
The reported result of therapeutic efficacy in the carprofen arm did support the validity of the results for the glucosamine and chondroitin arm. However, the absence of a comparator placebo arm in the study design calls into question whether the glucosamine and chondroitin arm was more or less effective as compared to placebo.

The authors claimed that glucosamine and chondroitin therapy was non-inferior to carprofen therapy at day 70 . Non-inferiority studies often require large sample sizes and rigorous statistical methods to demonstrate noninferiority between two treatments. The decision to use a sample size that provided $78 \%$ power to detect a difference in the median subjective veterinarian assessment score of one point was questionable and lacking in transparency of statistical method design. A median reduction of one point in the subjective veterinarian assessment score represented a clinically significant improvement in the canines' condition, but justification for selection of this score was absent.

Clinical trials: Glucosamine/chondroitin versus undenatured collagen type II, placebo, or glucosamine/chondroitin/undenatured collagen type II

Gupta et al. (2012) conducted a prospective, randomized, double-blinded study that included approximately 31-37 client-owned dogs weighing $>40$ lbs with moderate osteoarthritis. The trial consisted of four arms in which the subjects received either 1) glucosamine $\mathrm{HCl}$, chondroitin sulfate, and undenatured collagen type II (UCII), 2) glucosamine $\mathrm{HCl}$ and chondroitin sulfate, 3) UCII, or 4) placebo. For complete dosing schedules, please see Table 2. Outcomes included therapeutic efficacy, tolerability, and safety. Efficacy was measured objectively through 
peak vertical force and impulse area measurements obtained with a piezoelectric sensor-based ground force plate (GFP) and subjectively through observational pain assessments on a monthly basis for 150 days. Additionally, the physical, hepatic, and renal functions of the dogs were monitored each month via body weight, temperature, pulse, alkaline phosphatase (ALP), alanine transaminase (ALT), bilirubin, blood urea nitrogen (BUN), and creatinine $(\mathrm{Cr})$ measurements. The placebo arm showed no statistically significant changes in any of the outcome measures by trial end. The glucosamine and chondroitin arm exhibited a significant reduction in subjectivelyassessed pain at 90 days with maximal effects observed at 150 days. The GFP-based parameters remained significantly unchanged by trial end. Supplementing glucosamine and chondroitin with UCII did not provide any additional benefit. None of the dogs receiving dietary supplements showed any signs of adverse effects.

Strengths of the Gupta et al. (2012) trial were that it was prospective, randomized, controlled, and doubleblinded. Weaknesses of the trial were that baseline patient characteristic information was not provided and the analysis protocol was vague.

Investigators in the D'Altilio et al. (2007) group conducted a prospective, randomized, double-blinded study that included 20 client-owned dogs with joint stiffness, lameness, moderate pain, swollen joints, difficulty getting up/down, and difficulty walking in horizontal areas or stairs due to osteoarthritis. The trial consisted of four arms in which the interventions were identical to those in the Gupta et al. (2012) trial. However, in contrast, intervention exposure lasted only 120 days followed by a 30-day withdrawal period. Outcomes included therapeutic efficacy and safety. Efficacy was measured subjectively through observational pain assessments on a monthly basis for 150 days. Additionally, body weight, hepatic function (ALT, bilirubin), and renal function (BUN, Cr) were measured each month to monitor for adverse effects. While the placebo arm exhibited no statistically significant changes in any of the outcome measures by trial end, the other results of the D'Altilio et al. (2007) trial differed from those of the Gupta et al. (2012) trial. The glucosamine and chondroitin arm showed a reduction in pain that was not significant and relapsed following the withdrawal of treatment for 30 days. As well, supplementing glucosamine and chondroitin with UCII did provide additional benefit to the point of reducing pain to a significant extent, although this benefit was also lost following the withdrawal of treatment for 30 days. None of the dogs receiving dietary supplements showed any signs of adverse effects. Strengths of the D'Altilio et al. (2007) trial were that it was prospective, randomized, controlled, and double-blinded. Weaknesses of the trial were that the baseline patient characteristics were unspecified and the follow-up and analysis protocol were unclear.

\section{Surrogate endpoint/in vitro studies}

In vitro studies investigating surrogate outcomes related to osteoarthritis treatment in dogs suggest that the use of glucosamine and chondroitin produces chondroprotective effects (Anderson et al., 1999). Currently, good-quality evidence does not exist to suggest that in vitro studies using surrogate endpoints translate into clinically meaningful improvements in canine osteoarthritis symptoms. Table 2 provides a brief summary of surrogate endpoint/in vitro trials for reader interest.

\section{Review articles}

Eight commentaries reviewing the evidence around glucosamine and chondroitin use in canines with osteoarthritis were available in the literature. These commentaries are presented below in chronological order from the time of publication.

The Pascoe (2002), Henrotin et al. (2005), and Neil et al. (2005) commentaries pre-date or opt not to discuss clinical trials investigating the use of glucosamine and chondroitin for pain reduction and improved mobility in canines. However, Pascoe (2002) notes that despite the lack of clinical evidence, $62 \%$ of surveyed veterinary practitioners reported recommending products containing glucosamine and chondroitin for canines because they believed that they were seeing beneficial effects with their use. Similarly, Henrotin et al. (2005) appear to give precedence to anecdote over scientific evidence by concluding that glucosamine and chondroitin have clearly demonstrated symptomatic action. Neil et al. (2005) concludes that the determination of the minimal effective concentrations of glucosamine and chondroitin and their beneficial effects in canines require further investigation.

The Johnston et al. (2008) commentary refers to the Aragon et al. (2007) systematic review, the Moreau et al. (2003) trial, and the McCarthy et al. (2007) trial. The authors conclude that despite having conflicting results, the two studies shared similar strengths such that one can have a moderate level of comfort with the results from both studies. In contrast, the Addleman commentary (Addleman, 2010) identifies the lack of high-quality clinical trials and objective measures of efficacy as well as the unknown absorption and duration of effect of nutraceuticals as limitations in the current evidence around glucosamine and chondroitin use in canines with osteoarthritis.

The author concludes that objective methods for measuring joint disease symptoms, mobility, and pain using force plate gait analysis, accelerometers, and validated pain scales need to be established and that effective glucosamine and chondroitin dosing needs to be determined using dogs as the study subjects, as 
canine dosing is currently extrapolated from studies conducted in other species and therefore suboptimal. Similarly, the McKenzie (2010) commentary concludes that clinical trial evidence is severely limited. The author calls for veterinarians to translate the uncertainty around the usefulness of glucosamine and chondroitin therapy when discussing this treatment option with dog owners. McKenzie (2010) points out that there is a lack of literature addressing the use of glucosamine and chondroitin as an adjunct to NSAID therapy.

KuKanich (2013) commentary concludes that current literature does not support the use of glucosamine and chondroitin for the control of osteoarthritis in dogs, although this conclusion appears to be based solely on the Moreau et al. (2003) trial. Finally, the Comblain et al. (2016) commentary objectively presents the negative results of the Moreau et al. (2003) trial in contrast to the relatively positive results of the McCarthy et al. (2007), D'Altilio et al. (2007), and Gupta et al. (2012) trials without offering any conclusions or recommendations.

\section{Discussion}

Nutraceuticals are not considered medicinal products and are consequently not regulated by the United States Food and Drug Administration (FDA); therefore manufacturers are not required to provide scientific information to legal authorities for approval (Vandeweerd et al., 2012).

Health Canada, through the Veterinary Drugs Directorate (VDD) has the mandate to set standards for, evaluate and monitor the safety, quality, and effectiveness of, and promote the prudent use of veterinary drugs including veterinary natural health products (Health Canada, 2013). Despite the trend towards more stringent criteria for veterinary nutraceutical products, the research community continues to conduct and publish novel, low-quality studies without consistent evaluation methods and varying products/doses.

The lack of high-quality, peer-reviewed literature makes it difficult to draw conclusions about therapies. Nutraceutical studies commonly have limitations related to methods of participant recruitment and randomization, baseline characteristic data reporting, intervention standardization and concealment, blinding, participant retention, follow-up procedures, and overall protocol. In contrast, background, objectives, interventions, and statistical results tend to be well-reported (Vandeweerd et al., 2012).

Based on the available literature, the potential benefits of glucosamine and chondroitin use in osteoarthritic canines can neither be confirmed nor denied. Glucosamine and chondroitin use in canines requires further clinical study using improved methodology. Clinical trials conducted to date have yielded mixed results.
These results are of questionable validity due to several trial shortcomings. First is the absence of therapeutic standardization. The sources of active ingredients, manufacturers of products, formulations, combinations of active ingredients, treatment doses, regimens, and durations of therapy differed significantly between trials. Second, multiple potential sources of bias were present in the trials, including the lack of a standardized follow-up timeframe, unexplained loss to follow-up, flawed study protocols, and incomplete data sets. Moreover, all of the clinical trials relied on subjective outcome measures to some extent, and the absence of standardized owner and veterinarian assessments increased the risk of bias in the reported results and diminished internal study validity.

The trials generally lacked peer review and were at risk of funding bias due to company sponsorship. Finally, there was an overall lack of generalizability of trial results. The trials were small in terms of the number of subjects used and subject baseline characteristics were not always disclosed. We cannot confidently extrapolate results from in-vitro studies using dogs with surgically/chemically-induced osteoarthritis to the client-owned dogs with naturally occurring osteoarthritis seen in practice.

\section{Future study design proposal}

From the above discussion, there is a clear need for a high-quality clinical study to evaluate the effect of glucosamine and chondroitin in canines with osteoarthritis. Table 3 proposes an ideal study design for a randomized clinical trial.

Our rationale for the study design aims to rectify common criticisms of previous study designs. We recommend conducting a multi-centered trial facilitated within veterinary orthopaedic surgery institutions and/or veterinary college institutions to eliminate funding bias. Client-owned dogs with naturally occurring osteoarthritis would be recruited and stratified according to disease severity (mild, moderate, or severe) using objective guideline measurements (i.e. radiographic imaging and semiobjective veterinary guideline assessment measurements).

Radiographic imaging to evaluate efficacy would include joint capsular distention, soft tissue thickening, and narrowed joint spaces. However, it is important to note that radiographic severity often does not correlate with clinical severity of disease. Thus, a standardized, semi-objective veterinary assessment would also be necessary for assessing disease severity and progression (Tilley and Smith, 2015). Once stratified, the dogs would be randomized into study arms using a central computerized system. All data collectors, analyzers, investigators, pet owners, subjects, and clinicians involved in the study would be blinded to the allocation of treatment. 
Table 3. Future Study Design Proposal.

\begin{tabular}{|c|c|}
\hline Patients & Client-owned dogs with naturally occurring osteoarthritis. \\
\hline Inclusion & $\begin{array}{l}\text { All breeds } \\
\text { Age }>1 \text { year } \\
\text { Weight }>20 \mathrm{~kg}\end{array}$ \\
\hline Exclusion & $\begin{array}{l}\text { Pregnancy; use of medications; hepatic, renal, or CV disease; gastrointestinal ulceration; bleeding } \\
\text { disorder; lameness due to infectious, immune-mediated, neurological, or neoplastic disease. }\end{array}$ \\
\hline Intervention & $\begin{array}{l}\text { Dosages and regimen: } 4 \text { treatment arms } \\
\text { 1) GHCl monotherapy } \\
\text { GHCl } 475 \mathrm{mg} \text { BID for dogs } 5-19.9 \mathrm{~kg} \\
\text { GHCl } 712.5 \mathrm{mg} \text { BID for dogs } 20-40 \mathrm{~kg} \\
\mathrm{GHCl} 950 \mathrm{mg} \text { for dogs }>40 \mathrm{~kg} \\
\text { 2) } \mathrm{GHCl} \text { and CS combination } \\
\mathrm{GHCl} 475 \mathrm{mg} / \mathrm{CS} 350 \mathrm{mg} \text { BID for dogs } 5-19.9 \mathrm{~kg} \\
\mathrm{GHCl} 712.5 \mathrm{mg} / \mathrm{CS} 525 \mathrm{mg} \text { BID for dogs } 20-40 \mathrm{~kg} \\
\text { GHCl 950mg/CS 700mg BID for dogs }>40 \mathrm{~kg} \\
\text { 3) Crystalline glucosamine sulfate (unknown dose) } \\
\text { 4) Placebo (control) } \\
\text { Formulation: Liquid (appears to produce higher peak concentrations in comparison to tablets) (Maxwell et } \\
\text { al., 2016). } \\
\text { Administration: With food (typical home environments would have intervention administered in } \\
\text { conjunction with food) (Maxwell et al., 2016). }\end{array}$ \\
\hline Control & Placebo (liquid). \\
\hline $\begin{array}{l}\text { Open Label } \\
\text { NSAID }\end{array}$ & Carprofen $2.2 \mathrm{mg} / \mathrm{kg} \mathrm{q} 12 \mathrm{~h}$. \\
\hline Randomization & Stratified randomization based on disease severity. \\
\hline $\begin{array}{l}\text { Allocation } \\
\text { Concealment }\end{array}$ & $\begin{array}{l}\text { Central computerized random allocation, with all assessors, investigators, analyzers, owners, clinicians, } \\
\text { and subjects blinded to treatment allocation. }\end{array}$ \\
\hline Outcome & $\begin{array}{l}\text { Primary outcomes: } \\
\text { 1. Subjective: The owner's assessment of the pet's clinical presentation and quality of life using a } \\
\text { standardized OA pain questionnaire (i.e. LOAD) } \\
\text { 2. Semi-objective: A standardized clinical pain and OA assessment by a veterinarian } \\
\text { 3. Objective: Radiographic changes, force plate gait analysis, static load bearing (to quantify reduced limb } \\
\text { loading (Tilley and Smith, 2015)), and kinematics } \\
\text { Secondary outcomes: Pharmacokintic characteristics of each dosage form, use of open-label NSAID, } \\
\text { safety outcomes (adverse effects) and client/patient adherence. }\end{array}$ \\
\hline Size & $\begin{array}{l}\text { Calculated using the clinically significant difference in primary outcome score, expected standard } \\
\text { deviation, and desired levels of confidence and power. }\end{array}$ \\
\hline $\begin{array}{l}\text { Baseline } \\
\text { Characteristics } \\
\text { Reported }\end{array}$ & $\begin{array}{l}\text { Disease severity, number and location(s) of affected joints, weight, age, breed, athletic history, disorders } \\
\text { that affect collagen or cartilage synthesis (Cushing's disease, diabetes mellitus, hypothyroidism) (Tilley } \\
\text { and Smith, 2015). }\end{array}$ \\
\hline Centre & Multi-centred, using veterinary or orthopaedic college institution(s). \\
\hline Duration & $\geq 90$ days (potentially 1 year of follow-up if funding permits). \\
\hline
\end{tabular}

(CS): Chondroitin sulfate; (GHCl): Glucosamine hydrochloride; (LOAD): Liverpool Osteoarthritis in Dogs; (OA): osteoarthritis.

Baseline characteristics including age, number of affected joints, location of affected joints, breed, weight, comorbidities, and other medications used would be included in the study. Appropriate inclusion and exclusion criteria would be pre-specified. The study size would need to be sufficiently large to ensure internal validity through statistical adjudication.

The intervention in our proposed study would ideally be a multi-arm trial. A prospective superiority trial would consist of 4 treatment arms: 1) glucosamine $\mathrm{HCl}$ monotherapy, 2) glucosamine $\mathrm{HCl}$ and chondroitin sulfate in combination, 3) crystalline glucosamine sulfate and 4) placebo. Glucosamine and chondroitin are slow-acting agents; therefore, a study examining their long-term use would be appropriate. Serial blood samples would be helpful to determine pharmacokinetic characteristics of the different dosage forms. We would recommend a trial of at least 90 days in duration, with possible extension to 1 year of followup. However, longer treatment duration is often limited by cost and client/patient adherence to medication regimen. Conditions of treatment administration could 
be further defined once efficacy has been established. A method of measuring compliance such as a clientcompleted dosing journal would be superior to reviewing the product returned by the owner, as dose absence does not necessarily equate to the successful administration of the dose. Additionally, analysing the data using both intention-to-treat and per-protocol analyses would establish the robustness of the results and reduce bias. For ethical reasons, allowing the openlabel use of a standardized NSAID regimen (carprofen or meloxicam) for all subjects as needed would be ethically appropriate. NSAID use would be documented for both study arms and could be reported as a secondary outcome. The risks of all the interventions would be presented and explained to each dog owner using informed consent.

It is important to note that when drawing conclusions from a study, statistically significant results are not always indicative of clinical importance (Addleman, 2010). Pre-defining clinically meaningful results prior to the trial would help to establish whether or not the glucosamine and chondroitin intervention would be advantageous for use. Minimizing the risk of type 1 or type 2 errors by conducting a proper sample size calculation is also essential for producing trustworthy study results.

Objective guidelines and measures would be used to assess the baseline severity of osteoarthritis, clinical disease progression, and benefits of therapy. Primary outcomes would also be measured with a semiobjective standardized clinical assessment conducted by veterinarians or orthopedic surgeons. A thorough history, physical examination, and standardized painrating scale as well as objective measures such as radiograph, force plate gait analysis, and kinematic results would all be essential for generating a complete picture of the canines in the trial.

Additionally, standardized pain and activity scoring tools completed by the dog owners would provide subjective data as an adjunct to the objective and semiobjective data. The Liverpool Osteoarthritis in Dogs' Clinical Metrology Instrument (LOAD) is a good option for gathering subjective data from the dog owners as it is easy to use, validated, and has demonstrated a correlation with force-platform data (Walton et al., 2013).

The LOAD tool considers the pet's background, lifestyle, and mobility; specifically, it assesses the pet's level of exercise, activity, lameness, and stiffness, as well as the effects of the weather. As mentioned earlier, secondary outcomes to measure may include the frequency of open-label NSAID use.

Future studies require greater transparency to promote educated recommendations by veterinarians and pharmacists to dog owners. Studies should always disclose complete information with regard to the ingredients present in an intervention, subject baseline data, dates of recruitment and follow up, references of publications used, data for every item measured, and data analysis methods used such that readers can interpret the results independently.

Studies should also report the flux of participants using a flow chart that specifies the number of patients that were eligible, excluded, included, stratified, randomized, treated as intended, analyzed for the primary outcome(s), and lost to follow-up (Vandeweerd et al., 2012). Reporting the number of patients lost to follow-up and documented reasons for drop-out is standard safety reporting for clinical trials. Authors should determine the risk versus benefit ratios objectively. Lastly, the authors' conclusions and interpretations should be consistent with the study results.

Once higher-quality randomized controlled trials have been conducted, the quality of systematic reviews would also increase. Additionally, well-structured observational studies would help limit the heterogeneity of the results and ensure that fair comparisons between studies are made (Addleman, 2010). Literature should also be peer-reviewed to make the interpretation of study results and their application to practice easier.

\section{Conclusion}

Glucosamine and chondroitin are commonly recommended by veterinarians as an alternative for treating osteoarthritis in canines unable to tolerate the adverse effects of NSAIDs, or as add-on therapy. Although glucosamine and chondroitin have benign adverse effect profiles, the clinical benefit of using these agents remains questionable. The available evidence is difficult to interpret due to the use of different manufacturers, salt forms, compositions, sources, strengths, regimens, therapy durations, and combinations of active ingredients. Further study is required in order to clarify the uncertainty around the clinical benefit of using these agents and quantify any treatment effect that exists.

\section{Conflict of interest statement}

The authors declare that there are no conflicts of interest regarding the writing of this paper.

\section{References}

Addleman, A. 2010. Evaluation of glucosamine hydrochloride/chondroitin sulfate nutraceuticals as a treatment to improve symptoms associated with canine and feline joint disease. Retrieved from https://www.banfield.com/Banfield/media/PDF/Do wnloads/CriticallyAppraisedTopics/2010_Winter_ CAT_Evaluation-of-Nutraceuticals.pdf

Adebowale, A., Du, J., Liang, Z., Leslie, J.L. and Eddington, N.D. 2002. The bioavailability and pharmacokinetics of glucosamine hydrochloride 
and low molecular weight chondroitin sulfate after single and multiple doses to beagle dogs. Biopharm. Drug Dispos. 23(6), 217-225.

Altman, R.D. 2009. Glucosamine therapy for knee osteoarthritis: pharmacokinetic considerations. Expert Rev. Clin. Pharmacol. 2(4), 359-371.

Anderson, C.C., Cook, J.L., Kreeger, J.M., Tomlinson, J.L. and Wagner-Mann, C.C. 1999. In vitro effects of glucosamine and acetylsalicylate on canine chondrocytes in three-dimensional culture. Am. J. Vet. Res. 60(12), 1546-1551.

Aragon, C.L., Hofmeister, E.H. and Budsberg, S.C. 2007. Systematic review of clinical trials of treatments for osteoarthritis in dogs. J. Am. Vet. Med. Assoc. 230(4), 514-521.

Beale, B.S. 2004. Use of nutraceuticals and chondroprotectants in osteoarthritic dogs and cats. Vet. Clin. North Am. Small Anim. Pract. 34(1), 271-289.

Canapp, S.O.Jr., McLaughlin, R.M.Jr., Hoskinson, J.J., Roush, J.K. and Butine, M.D. 1999. Scintigraphic evaluation of dogs with acute synovitis after treatment with glucosamine hydrochloride and chondroitin sulfate. Am. J. Vet. Res. 60(12), 15521557.

Comblain, F., Serisier, S., Barthelemy, N., Balligand, M. and Henrotin, Y. 2016. Review of dietary supplements for the management of osteoarthritis in dogs in studies from 2004 to 2014. J. Vet. Pharmacol. Ther. 39(1), 1-15.

D'Altilio, M., Peal, A., Alvey, M., Simms, C., Curtsinger, A., Gupta, R.C., Canerdy, T.D., Goad, J.T., Bagchi, M. and Bagchi, D. 2007. Therapeutic Efficacy and Safety of Undenatured Type II Collagen Singly or in Combination with Glucosamine and Chondroitin in Arthritic Dogs. Toxicol. Mech. Methods 17(4), 189-196.

Epstein, M., Rodan, I., Griffenhagen, G., Kadrlik, J., Petty, M., Robertson, S. and Simpson, W. 2015. 2015 AAHA/AAFP Pain Management Guidelines for Dogs and Cats. Retrieved from https://www.aaha.org/public_documents/professio nal/guidelines/2015_aaha_aafp_pain_management _guidelines_for_dogs_and_cats.pdf

Extend Joint Care. 2016. Extend For a Longer, Better Life. Retrieved from https://www.extendpetcare.com/

Gupta, R.C., Canerdy, T.D., Lindley, J., Konemann, M., Minniear, J., Carroll, B.A., Hendrick, C., Goad, J.T., Rohde, K., Doss, R., Bagchi, M. and Bagchi, D. 2012. Comparative therapeutic efficacy and safety of type-II collagen (UC-II), glucosamine and chondroitin in arthritic dogs: pain evaluation by ground force plate. J. Anim. Physiol. Anim. Nutr. (Berl) 96(5), 770-777.
Health Canada. 2013. Drugs and Health Products: Veterinary Drugs. Retrieved from http://www.hcsc.gc.ca/dhp-mps/vet/index-eng.php.

Henrotin, Y., Sanchez, C. and Balligand, M. 2005. Pharmaceutical and nutraceutical management of canine osteoarthritis: present and future perspectives. Vet. J. 170(1), 113-123.

Herrero-Beaumont, G., Ivorra, J.A., Del Carmen Trabado, M., Blanco, F.J., Benito, P., Martin-Mola, E., Paulino, J., Marenco, J.L., Porto, A., Laffon, A., Araujo, D., Figueroa, M. and Branco, J. 2007. Glucosamine sulfate in the treatment of knee osteoarthritis symptoms: a randomized, doubleblind, placebo-controlled study using acetaminophen as a side comparator. Arthritis Rheum. 56(2), 555-567.

Johnson, K.A., Hulse, D.A., Hart, R.C., Kochevar, D. and Chu, Q. 2001. Effects of an orally administered mixture of chondroitin sulfate, glucosamine hydrochloride and manganese ascorbate on synovial fluid chondroitin sulfate 3B3 and 7D4 epitope in a canine cruciate ligament transection model of osteoarthritis. Osteoarthritis Cartilage 9(1), 14-21.

Johnston, S.A. 1997. Osteoarthritis. Joint anatomy, physiology, and pathobiology. Vet. Clin. North Am. Small Anim. Pract. 27(4), 699-723.

Johnston, S.A., McLaughlin, R.M. and Budsberg, S.C. 2008. Nonsurgical management of osteoarthritis in dogs. Vet. Clin. North Am. Small Anim. Pract. 38(6), 1449-1470.

KuKanich, B. 2013. Outpatient oral analgesics in dogs and cats beyond nonsteroidal antiinflammatory drugs: an evidence-based approach. Vet. Clin. North Am. Small Anim. Pract. 43(5), 1109-1125.

Liquid Health Inc. 2016. K9 Glucosamine for Dogs Joint Supplement. Retrieved from http://liquidhealthpets.com/products/k9glucosamine-for-dogs.

Maxwell, L.K., Regier, P. and Achanta, S. 2016. Comparison of Glucosamine Absorption After Administration of Oral Liquid, Chewable, and Tablet Formulations to Dogs. J. Am. Anim. Hosp. Assoc. 52(2), 90-94.

McCarthy, G., O'Donovan, J., Jones, B., McAllister, H., Seed, M. and Mooney, C. 2007. Randomised double-blind, positive-controlled trial to assess the efficacy of glucosamine/chondroitin sulfate for the treatment of dogs with osteoarthritis. Vet. J. 174(1), 54-61.

McKenzie, B.A. 2010. What is the evidence? There is only very weak clinical trial evidence to support the use of glucosamine and chondroitin supplements for osteoarthritis in dogs. J Am Vet Med Assoc, 237(12), 1382-1383. 
Meulyzer, M., Vachon, P., Beaudry, F., Vinardell, T., Richard, H., Beauchamp, G. and Laverty, S. 2008. Comparison of pharmacokinetics of glucosamine and synovial fluid levels following administration of glucosamine sulphate or glucosamine hydrochloride. Osteoarthritis Cartilage, 16(9), 973979.

Moreau, M., Dupuis, J., Bonneau, N.H. and Desnoyers, M. 2003. Clinical evaluation of a nutraceutical, carprofen and meloxicam for the treatment of dogs with osteoarthritis. Vet. Rec. 152(11), 323-329.

Neil, K.M., Caron, J.P. and Orth, M.W. 2005. The role of glucosamine and chondroitin sulfate in treatment for and prevention of osteoarthritis in animals. J. Am. Vet. Med. Assoc. 226(7), 1079-1088.

Nutramax Laboratories Veterinary Sciences Inc. 2016a. Cosequin Joint Health Supplement. Retrieved http://www.cosequin.com/dogs/joint-andbone/cosequin-professional-line/cosequin-dsmaximum-strength

Nutramax Laboratories Veterinary Sciences Inc. 2016b. Dasuquin with MSM. Retrieved from http://www.nutramaxlabs.com/dog/dog-joint-bonehealth/dasuquin-for-dogs

Pascoe, P.J. (2002). Alternative methods for the control of pain. J. Am. Vet. Med. Assoc. 221(2), 222-229.

Persiani, S., Roda, E., Rovati, L.C., Locatelli, M., Giacovelli, G. and Roda, A. 2005. Glucosamine oral bioavailability and plasma pharmacokinetics after increasing doses of crystalline glucosamine sulfate in man. Osteoarthritis Cartilage, 13(12), 1041-1049.

Pet Naturals of Vermont. 2016. Animal Health Products: Hip + Joint Extra Strength. Retrieved from

http://www.petnaturals.com/index.php?l=product_ detail\&p=700523120

PetMed Express Inc. 2016. ProMotion for Medium Large Dogs. Retrieved from http://www.1800petmeds.com/ProMotion+For+M edium+Large+Dogs-prod10490.html

Plumb, D.C. 2015. Glucosamine/Chondroitin Sulfate. In: Plumb's Veterinary Drug Handbook (Eighth ed.). Stockholm, Wiscoconsin, USA: Pharma Vet Inc.

Roush, J.K., McLaughlin, R.M. and Radlinsky, M.G. 2002. Understanding the pathophysiology of osteoarthritis. Vet Med. 97, 108-117.

Rovati, L.C., Girolami, F. and Persiani, S. 2012.
Crystalline glucosamine sulfate in the management of knee osteoarthritis: efficacy, safety, and pharmacokinetic properties. Ther. Adv. Musculoskelet. Dis. 4(3), 167-180.

Rychel, J.K. 2010. Diagnosis and treatment of osteoarthritis. Top Companion Anim. Med. 25(1), 20-25.

Sawitzke, A.D., Shi, H., Finco, M.F., Dunlop, D.D., Harris, C.L., Singer, N.G., Bradley, J.D., Silver, D., Jackson, C.G., Lane, N.E., Oddis, C.V., Wolfe, F., Lisse, J., Furst, D.E., Bingham, C.O., Reda, D.J., Moskowitz, R.W., Williams, H.J. and Clegg, D.O. 2010. Clinical efficacy and safety of glucosamine, chondroitin sulphate, their combination, celecoxib or placebo taken to treat osteoarthritis of the knee: 2-year results from GAIT. Ann. Rheum. Dis. 69(8), 1459-1464.

Setnikar, I. and Rovati, L.C. 2001. Absorption, distribution, metabolism and excretion of glucosamine sulfate. A review. Arzneimittelforschung 51(9), 699-725.

TerraMax Pro. 2016. Hip \& Joint Supplement for Dogs. Retrieved from http://terramaxpro.com/product/hipjoint/

Tilley, L.P. and Smith, F.W.K.Jr. 2015. Arthritis (Osteoarthritis). In: Blackwell's Five-Minute Veterinary Consult: Canine and Feline (Sixth ed.): Wiley Blackwell.

Vandeweerd, J.M., Coisnon, C., Clegg, P., Cambier, C., Pierson, A., Hontoir, F., Saegerman, C., Gustin, P. and Buczinski, S. 2012. Systematic review of efficacy of nutraceuticals to alleviate clinical signs of osteoarthritis. J. Vet. Intern. Med. 26(3), 448456.

Vetri-Science Laboratories. 2016. Glyco-Flex III Soft Chews. Retrieved from http://www.glycoflex3.com/info.html

Walton, M.B., Cowderoy, E., Lascelles, D. and Innes, J.F. 2013. Evaluation of construct and criterion validity for the 'Liverpool Osteoarthritis in Dogs' (LOAD) clinical metrology instrument and comparison to two other instruments. PLoS One 8(3), e58125. doi:10.1371/journal.pone.0058125.

Wandel, S., Juni, P., Tendal, B., Nuesch, E., Villiger, P.M., Welton, N.J., Reichenbach, S. and Trelle, S. 2010. Effects of glucosamine, chondroitin, or placebo in patients with osteoarthritis of hip or knee: network meta-analysis. BMJ. 341, c4675. doi:10.1136/bmj.c4675 